\title{
MicroscopyPioneers
}

\section{Pioneers in Optics: Robert Day Allen}

\author{
Michael W. Davidson
}

National High Magnetic Field Laboratory, Florida State University, Tallahassee, FL 32306

davidson@magnet.fsu.edu

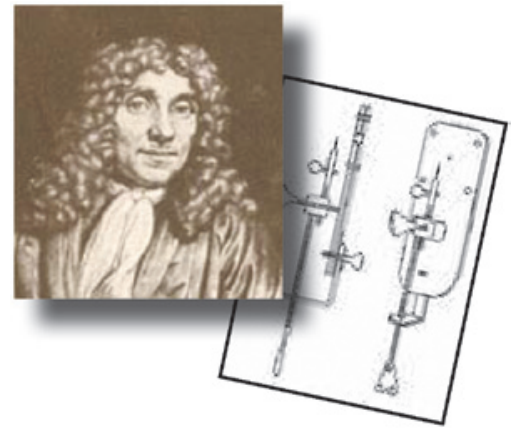

\section{Robert Day Allen \\ (1927-1986)}

Robert Day Allen was a renowned microscopist, as well as a prominent researcher of cell motility processes, and a co-developer of video-enhanced contrast (VEC) microscopy, which is a modification of the traditional form of differential interference contrast (DIC) microscopy. He also served as a professor at Dartmouth College and the Marine Biological Laboratory (MBL) in Wood's Hole, Massachusetts, publishing numerous scientific works during his lifetime. Some of his most important scientific contributions were made together with his wife and fellow scientist Nina Strömgren Allen.

In the midst of teaching a short summer optical microscopy course at the Marine Biological Laboratory, the Allens, who were both faculty members at Dartmouth, made a surprise discovery. When Nina Strömgren Allen and Jeff

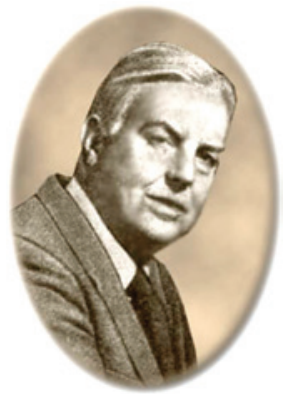
Travis attached a video camera and television to a microscope in order to enable Robert Allen to present a preparation to the entire class for simultaneous viewing, they discovered that sub-resolution structures could be imaged with video differential contrast that are not ordinarily observed with the resolutions available using a conventional light microscope. Although an electron microscope is able to display even smaller objects, the preparations must be fixed. The video microscopy technique that the Allens developed is capable of imaging specimens that are alive and mobile.

DIC is also an excellent mechanism for rendering contrast in transparent specimens. It is a beam-shearing interference system in which the reference beam is sheared by a minuscule amount, generally somewhat less than the diameter of an Airy disk. The technique produces a monochromatic shadow-cast image that effectively displays the gradient of optical paths for both high and low spatial frequencies present in the specimen. Those regions of the specimen where the optical paths increase along a reference direction appear brighter (or darker), whereas regions where the path differences decrease appear in reverse contrast. As the gradient of optical path difference grows steeper, image contrast is dramatically increased.

Along with Georges Nomarski and George B. David, Robert Day Allen assisted the Carl Zeiss Optical Company in developing a Nomarski differential interference microscope for transmitted light applications. In a hallmark paper published in Zeitschrift für wissenschaftliche Mikroskopie und mikroskopische

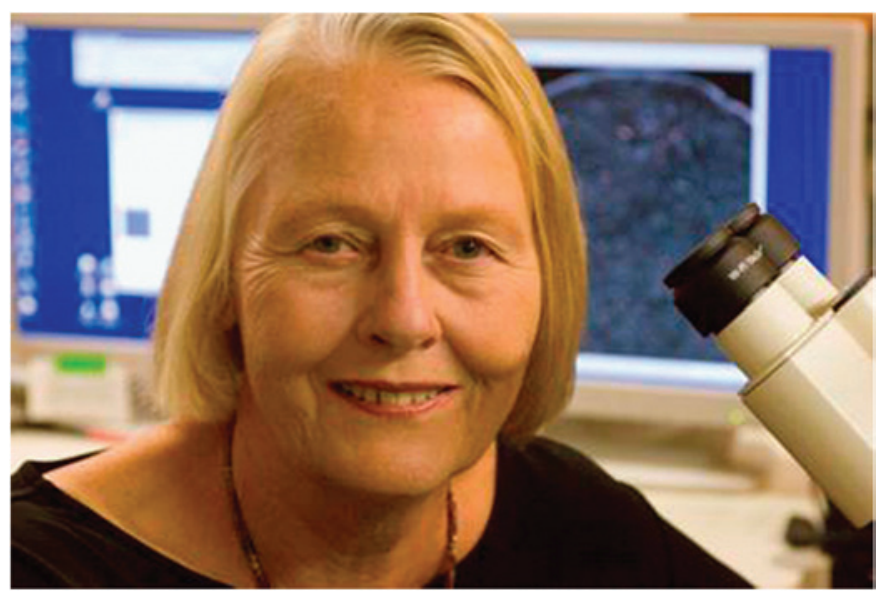

Nina Strömgren Allen, a co-developer of VIC microscopy with Robert Day Allen, her husband.

Technik, Allen and his colleagues defined the basic principles of the DIC technique and the interpretation of images.

Robert Allen worked with Nina Strömgren Allen to modify the camera and microscope configuration in a manner that allowed for maximum resolution, contrast, and magnification. The pair and Shinya Inoué, who was a resident scientist at MBL and an invited lecturer in the Allens's microscopy course, described the new method at a meeting of the American Society for Cell Biology. Then in 1982, the Allens advanced their work by capturing video images digitally and then used a frame memory to analyze and quantify images. On October 25, 1983, the couple received a United States patent for their development of Allen Video Enhanced light microscopy.

Video microscopy, alone and coupled to differential interference contrast optical systems, is now commonly used in laboratories around the world and has proved especially useful in the study of cell biology. For example, the technique enabled the real-time observation of microtubules, with which Allen was directly involved, and ultimately led to the detection of the motor molecule kinesin. In addition, Allen was able to visualize objects that were below the limit of resolution of the light microscope and were normally observed only with an electron microscope.

In 1986, Allen died from cancer. The Robert Day Allen Fellowship, offered through the Marine Biological Laboratory, was created in his memory and is awarded annually to a young researcher dedicated to the study of cellular motility and anatomy. 


\section{The single source for all your microscopy supplies and specimen preparation equipment.}

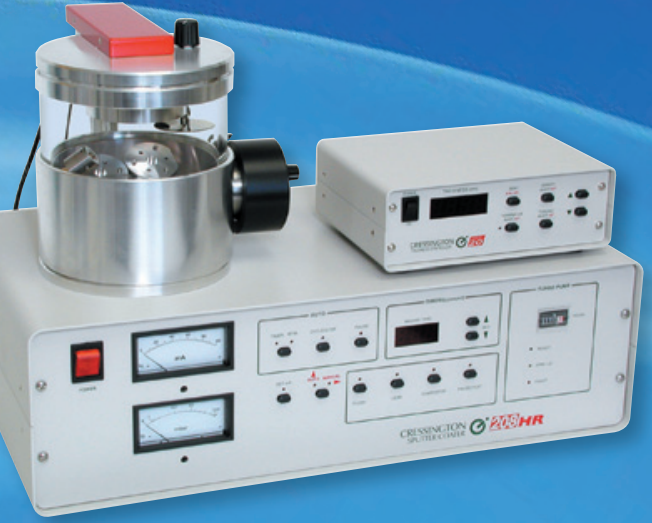

EM Coating Systems

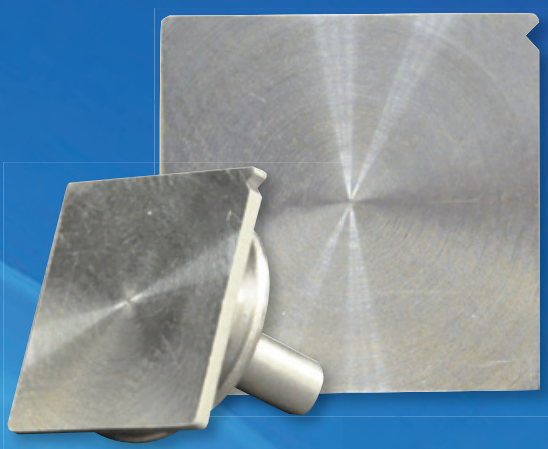

PELCO ${ }^{\circledR}$ Q Pin Stubs for Correlative Microscopy

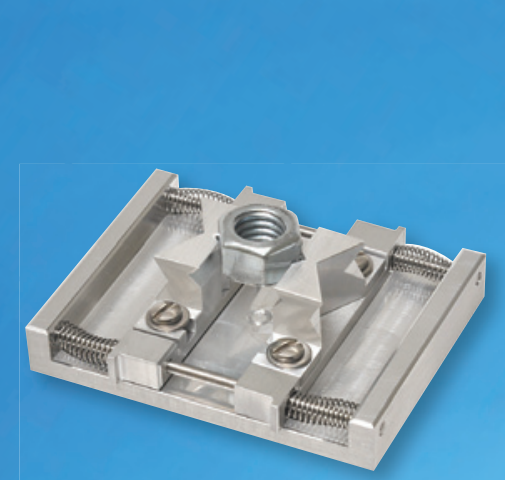

SEM Supplies

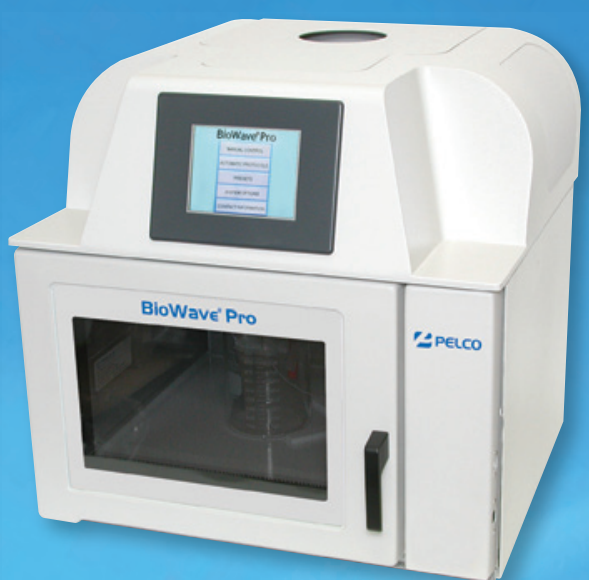

PELCO BioWave ${ }^{\circledR}$ Pro

Tissue Processor

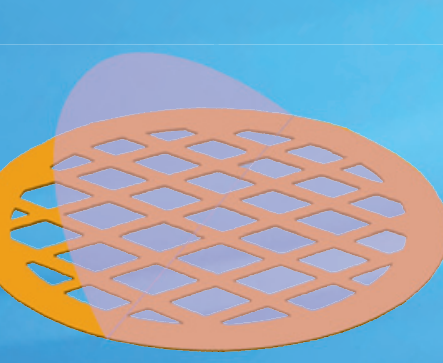

TEM Supplies

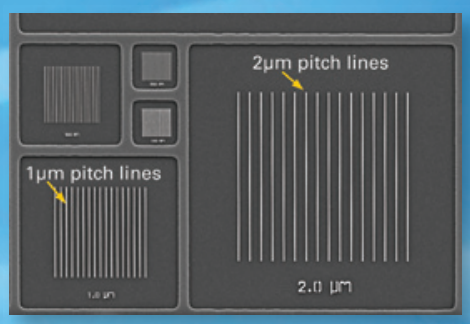

Microscope Calibration

\section{○ TED PELLA, INC.

